\title{
PROSPECTS OF ACINETOBACTER CALCOACETICUS IMV B-7241 METABOLITES USE IN AGRICULTURE
}

\author{
T. P. Pirog, N. O. Leonova, I. V. Savenko, G. O. Iutynska
}

In the last decade, the increasing resistance of pathogen microorganisms to known biocides is observed, that led to the search for new alternative antimicrobial agents. From the literature it is known that these agents are microbial surfactants (SAS) [1-3]. Due to ecological safety the SAS of microbial origin can be used in medicine, agriculture sector and food industry [1-5].

Mostly the literature reports of antifungal activity of SAS on plant pathogens [6-8], but except fungal diseases, agricultural crops are increasingly influenced by bacterioses [9].

Earlier, we isolated oil-degrading bacteria from oil-contaminated soil samples identified as Acinetobacter calcoaceticus K-4 (IMV B-7241) and the capacity of strain to synthesize metabolites with surface-active and emulsifying properties at various hydrophobic and hydrophilic substrates was determined [10-12].

In previous studies $[13 ; 14]$ we also found that the surfactants synthesized by $A$. calcoaceticus IMV B-7241 possess antimicrobial properties as for the number of microorganisms (Bacillus subtilis BT-2, Escherichia coli IEM-1, Candida tropicalis PBT-5, Candida albicans D-6, Candida utilis BVC-65). Meanwhile, it is shown that in some cases the treatment of test culture suspension with supernatant containing surfactants was accompanied by the increase in the number of living cells compared to their number before the addition of surfactants [14]. Later it was shown that aqueous phase, which remained after the extraction of SAS from culture liquid supernatant, stimulated the growth of some bacteria cells. These unexpected results enabled suggesting that investigated strains-producers of SAS, in addition to complex surfactants, synthesize other biologically active compounds, including plant hormones.

In connection with the above the objective of this work is the study of antimicrobial action of surfactants of $A$. calcoaceticus IMV B-7241 as for phyto-pathogenic bacteria, and the ability of IMV B-7241 strain to synthesize of plant hormones.

Materials and methods. The main object of the research was $A$. calcoaceticus $\mathrm{K}-4$ strain, registered in the Depository of microorganisms of Zabolotny Institute of Microbiology and Virology of National Academy of Sciences of Ukraine under the number IMV B-7241.

SAS of $A$. calcoaceticus IMV B-7241 were found to contain glyco- (trehalose mono- and dimycolates, trehalose mono- and diacelates) and aminolipids [11].

The research used phytopathogenic bacteria from Ukrainian collection of microorganisms (UCM): Pectobacterium carotovorum UCM B-1095, Pseudomonas syringae UCM B-1027, P. syringae pv. atrofaciens $\mathrm{UCM} \mathrm{B}-1015, P$. syringae pv. coronafaciens UCM B-1154, Xanthomonas campestris pv. campestris UCM B-1049.

The objects of the study were also phytopathogenic bacteria from the collection of the department of pathogenic bacteria of D. K. Zabolotny Institute of Microbiology and Virology of NAAS of Ukraine: $P$. corrugate 9070, $P$. savastanoi pv. glycinea $8571, X$. translucens pv. translucens 7696, $X$. vesicatoria 7790.

For A. calcoaceticus IMV B-7241 cultivation the culture medium of such composition was used (g/l): $\left(\mathrm{NH}_{2}\right)_{2} \mathrm{CO}-0.35$; $\mathrm{MgSO}_{4}-7 \mathrm{H}_{2} \mathrm{O}-0.1 ; \mathrm{NaCl}-1.0 ; \mathrm{Na}_{2} \mathrm{HPO}_{4}-$ $0.6 ; \mathrm{KH}_{2} \mathrm{PO}_{4}-0.14 ; \mathrm{pH}$ 6.8-7.0. In addition yeast autolysate was added to the medium $0.5 \%$ (volume fraction) and micronutrients solution - $0.1 \%$ (volume fraction) [11]. The source of carbon - ethanol, glycerine, and sunflower oil refined and wasted after meat frying at the concentration of $1 \%$ (volume fraction). The culture from the exponential growth phase grown on the above medium composition was used as inoculants which contained $0.5 \%$ of a corresponding substrate (carbon source). The amount of seed material $\left(10^{4}-10^{5}\right.$ cells $\left./ \mathrm{ml}\right)$ made $10 \%$ of the culture medium volume. The cultivation of bacteria was carried in $750 \mathrm{ml}$ flasks with $100 \mathrm{ml}$ of 
medium on a shaker $\left(320 \mathrm{rev} . / \mathrm{min}\right.$.) at $28-30^{\circ} \mathrm{C}$ for 120 hours.

From the culture liquid supernatant containing SAS (preparation 1), SAS (preparation 2) was isolated by the extraction with the mixture of chloroform and methanol in the ratio of 2:1 (Folch mixture). The aqueous phase which remained after the extraction of SAS, was conventionally called preparation 3 by us.

The cells of producers were separated by centrifugation $(5000 \mathrm{~g})$ for $45 \mathrm{~min}$, the supernatant (preparation 1) was further processed. To do this, $50 \mathrm{ml}$ of the supernatant were placed in a cylindrical separating $200 \mathrm{ml}$ funnel, $50 \mathrm{ml}$ of Folch mixture was added, the funnel was closed with ground stopper and shaken (extracted lipids) for $5 \mathrm{~min}$. The resulting mixture was left in the separating funnel after the extraction for phase separation, after what the bottom fraction was poured off (organic extract 1) and the aqueous phase was subject to re-extraction as described above. After the phase separation the bottom fraction was poured off, thus getting organic extract 2 . At the third stage $50 \mathrm{ml}$ of Folch mixture were added to the aqueous phase, the extraction was performed to obtain the organic extract 3 . Extracts 1-3 were combined and evaporated on a rotary evaporator IP $1 \mathrm{M} 2$ (Russia) at $50^{\circ} \mathrm{C}$ and absolute pressure of $0.4 \mathrm{~atm}$. to get constant weight. The dry residue was dissolved in sterile drinking water to the original volume. Preparations were sterilized at $112^{\circ} \mathrm{C}$ for 30 min. The concentration of SAS in preparations 1 and 2 was set by weighing technique after the extraction with Folch mixture.

The antimicrobial properties of preparations were determined as follows. In the initial suspension of one-day phyto-pathogenic test cultures grown on agar medium (wort agar-agar and meat-and-peptone agar in the ratio $1: 1$ ) at $30^{\circ} \mathrm{C}$, the number of living cells was determined by Koch's method (colony-forming units, CFU/ml). Then $1.5 \mathrm{ml}$ of test culture suspension were placed in test tubes, added preparations 1-3 in the amount of $1.5 \mathrm{ml}$ each and kept within 1 and 2 hours at the temperature optimal for growth of test culture, and what the number of living cells was determined.

The survival of pathogenic bacteria was determined as the ratio of the number of cells in variants treated with preparations 1-3 to the number of cells in the initial suspension and was expressed as a percentage.

Extracellular phytohormones - auxins, cytokinins and abscisic acid (ABA) - were isolated from $A$. calcoaceticus IMV B-7241 culture liquid supernatant by the method of phytohormones redistribution in two immiscible with each other phases of solvents: ethyl acetate (for auxins and ABA), $\mathrm{pH}$ 3.0; n-butanol (for cytokinins), $\mathrm{pH} 8.0$ [15]. The resulting extracts were evaporated in vacuum at $40-45^{\circ} \mathrm{C}$, dry residue was dissolved in ethanol and used for physical and chemical analysis of phytohormones.

Prior purification and concentration of phytohormones was performed on silica gel plates "Silufol UV254" (Chemapol, Czechoslovakia) in the mixture of solvents used sequentially: chloroform, $12.5 \%$ solution of aqueous ammonia, ethyl acetate, acetic acid $(20: 1)$. Extracts of cytokinins, ABA and indole compounds, purified in such a way, were separated on plates with aluminium and silica oxide (Merck, Germany) as described in the work [16]. The numeric determination of phytohormones was performed with a scanning spectrodensitometer Sorbfil (Russia); synthetic plant hormones of Sigma-Aldrich (Germany) and Acros Organics (Belgium) were used as standards. The number of extracellular phytohormones was calculated in $\mu \mathrm{g} / \mathrm{l}$ of supernatant.

All experiments were performed in 3 repetitions, the number of parallel measurements in experiments ranged from 3 to 5. The statistical analysis of the experimental data was performed as previously described [10-12]. The differences of averages were considered probable at the significance level of $\mathrm{p}<0.05$.

The obtained results show the possibility of using oil-containing industrial waste for simultaneous synthesis both surfactants and phytohormones. These data is the basis for the implementation of non-waste technology, giving an opportunity to get microbial preparations with different biological properties in one process. Thus, when SAS preparations are obtained, precipitated cells can be used for water purification from oil [12]; the 
resulting culture liquid supernatant - for further isolation of surfactants with antimicrobial antiadhesive (including pathogenic bacteria) properties $[13 ; 14 ; 20]$. Whereas, the aqueous phase that remains after the extraction of SAS contains plant hormones of auxin and cytokinin origin, it can be used to stimulate the growth of microorganisms and plants. 